CONGRESO INTERNACIONAL 70 ANIVERSARIO DECLARACIÓN UNIVERSAL DE DERECHOS HUMANOS

\title{
70 años de la Declaración Universal de Derechos Humanos: introducción a una colección plural de reflexiones \\ 70 years of the Universal Declaration of Human Rights: an introduction to a plural collection of reflections
}

\author{
Jose Antonio García Sáez \\ Institut de Drets Humans \\ Universitat de València
}

\section{RESUMEN.}

Tras una breve reflexión introductoria, este texto presenta algunos de los trabajos derivados del Congreso Internacional sobre el 70 Aniversario de la Declaración Universal de Derechos Humanos, que tuvo lugar en Valencia en diciembre de 2018. Los trabajos se han clasificado en siete secciones: 1) Ponencias invitadas; 2) Violencia de género y derechos de las mujeres; 3) Empresas multinacionales y derechos humanos; 4) Memoria histórica y derechos humanos; 5) Nuevos escenarios y nuevas garantías para los derechos; 6) Contextos y vulnerabilidades; 7) Perspectivas.

\section{PALABRAS CLAVE.}

Derechos humanos, filosofía del derecho, derecho internacional

\section{ABSTRACT.}

After a brief introductory reflection, this text presents some of the works derived from the International Congress on the 70th Anniversary of the Universal Declaration of Human Rights that took place in Valencia in December 2018. The works have been classified into seven sections: 1) Guest lectures 2) Gender violence and women's rights; 3) Multinational companies and human rights; 4) Historical memory and human rights; 5) New scenarios and new guarantees for rights; 6) Contexts and vulnerabilities; 7) Perspectives.

\section{KEY WORDS.}

Human rights, philosophy of law, international law 
Vivimos en un mundo en el que 3.500 millones de personas, la mitad de la humanidad, vive con menos de 5,5 dólares al día, mientras que la riqueza de unos pocos milmillonarios aumenta al ritmo de 2.500 millones de dólares al día. Un mundo en el que los hombres poseen un 50\% más de la riqueza mundial que las mujeres (Oxfam, 2019: 8). Nunca tantas personas a nivel mundial se han visto forzadas a dejar su hogar a causa de guerras y situaciones de violencia generalizada, alcanzando los 70 millones (CEAR, 2018). En los tres primeros meses de 2019, más de 500 personas se han ahogado en el Mediterráneo tratando de encontrar un lugar seguro donde vivir (IOM, 2019) mientras los barcos de rescate de varias organizaciones de salvamento marítimo permanecen bloqueadas por los gobiernos europeos.

La proclamación de la Declaración Universal de Derechos Humanos y el posterior desarrollo que el derecho internacional de los derechos humanos ha experimentado en los últimos 70 años es lo que nos permite decir que situaciones como estas no solamente son injustas desde el punto de vista moral, sino que suponen vulneraciones desde el punto de vista jurídico. La cultura de los derechos humanos nos previene de contemplar estas cifras como meras fatalidades. Nos obliga a actuar. Pone sobre todos nosotros - y particularmente sobre quienes tienen responsabilidades públicas - el deber de no mirar para otro lado, de tomar partido para terminar con las vulneraciones, reparar a las víctimas y establecer las garantías para que tales vulneraciones no se vuelvan a repetir.

La Declaración Universal significó más un punto de partida que una culminación (Hunt, 2007: 207). En la cultura jurídica de mediados del siglo XX no parecía tan claro qué posición debían ocupar los derechos humanos dentro del mundo del derecho. Si tomamos, por ejemplo, a Kelsen como una de sus grandes figuras, podemos comprobar sus dudas respecto del valor de la Declaración: "resulta evidente que la resolución de la Asamblea General sobre los derechos humanos no tiene ningún efecto jurídico [...] la afirmación de que todos los seres humanos nacen libres e iguales [...] está muy lejos de ser generalmente aceptada" (1950: 40). No obstante, esta visión resulta afortunadamente minoritaria en la academia contemporánea. Hoy encontramos posiciones ampliamente influyentes, como las de Dworkin, Alexy o Ferrajoli, que sitúan los derechos en el centro de nuestros ordenamientos jurídicos. El derecho ya no puede ser un simple conjunto (o un sistema) de normas formales, sino que posee unos contenidos mínimos que vienen determinados por el respeto a los derechos humanos. 
Sin la Declaración Universal ese cambio — que, con toda justicia, puede ser identificado como un cambio de paradigma (Ferrajoli, 2011a: 775) — no puede ser entendido. Una influencia fundamental en la Declaración fue el libro del internacionalista Hersch Lauterpacht An International Bill of Rights (1945). En él, Lauterpacht toma explícitamente el encargo de Winston Churchill para consagrar o poner en un trono (enthronement) los derechos humanos (Sands, 2013: xxii). La palabra elegida por Churchill resulta muy significativa: la única manera de evitar que los horrores del holocausto y de los totalitarismos se volvieran a producir era situar los derechos humanos en una posición supraordinada al resto de normas jurídicas o directrices políticas. Los derechos humanos debían ser vistos así como la clave de bóveda de los ordenamientos jurídicos. Tanto de los ordenamientos nacionales como del derecho internacional. Debían convertirse en algo no negociable, algo no sometido al vaivén de las coyunturas políticas o económicas. Un sustrato común del que partir para habitar un mundo en paz.

Los derechos humanos son, por lo tanto, derecho. Son, podría decirse, el corazón del derecho. Pero son también mucho más que derecho. Los y las juristas no tenemos el monopolio para hablar sobre los derechos humanos. Antes al contrario, son un patrimonio común de la humanidad. La historiadora Lynn Hunt (2007:35) ha desarrollado una conocida tesis sobre la influencia de literatura en la consolidación de la idea de derechos humanos a lo largo del siglo XVIII. El conocimiento de otras culturas, otras formas de vida, se hace posible con la difusión de las novelas al gran público. Y ese hecho, sostiene Hunt, supuso un paso imprescindible para crear la empatía con lo diferente que es, a su vez, el sustrato que permite crear la idea de igualdad. Desde el momento en que hay igualdad en lo humano, en que hay reconocimiento mutuo, cualquier afrenta a la dignidad de una persona, cualquier trato discriminatorio a cualquier persona, resulta una potencial afrenta a la propia humanidad. Nace así la idea de universalidad en la igualdad en derechos. Y para entender este paso, en efecto, no basta con los conocimientos que proporciona el derecho: necesitamos de la historia, de la filosofía, de la psicología, de la literatura y, en definitiva, de cualquier rama del saber.

Pero también nos equivocaríamos si pensáramos que los derechos humanos son una cuestión puramente académica. Algo sobre lo que únicamente se pueden permitir pensar quienes se encuentran en la acomodada posición de un despacho. Los derechos humanos son algo vivo y dinámico. Son el producto de luchas sociales y constantes procesos conflictuales. Las instituciones, nacionales e internacionales, suponen instancias fundamentales para la defensa de los derechos humanos. Pero no 
son suficientes. Los estados pueden cuidar de nuestros derechos, pero son al mismo tiempo — por la cantidad de poder que acumulan - máquinas de violar derechos. Por eso necesitan una vigilancia constante y activa de la ciudadanía. Sea cual sea el color del gobierno, los derechos necesitan quien los defienda, quien esté dispuesto a alzar la voz por quienes no la tienen. En ese sentido cobra una importancia política fundamental la protección de las personas defensoras de los derechos humanos. Lo mismo cabe decir para quienes se dedican al periodismo, cuya labor — cuando es digna de ese nombre - es imprescindible para fiscalizar al poder y exigirle rendir cuentas. Jhering supo plasmar como nadie ese espíritu combativo de los derechos humanos: "todo derecho en el mundo debió ser adquirido por la lucha" (2008: 32).

Bajo esa idea, todos estos puntos de vista tuvieron cabida en el Congreso sobre el 70 Aniversario de la Declaración Universal de Derechos Humanos, que se celebró en Valencia entre los días 10 y 12 de diciembre de 2018 organizado por el Institut de Drets Humans de la Universitat de València ${ }^{1}$ y dirigido por el profesor Javier de Lucas. En este número especial de Cuadernos Electrónicos de Filosofía del Derecho se recogen algunos de los trabajos expuestos en el Congreso, que a continuación presentaré y comentaré muy brevemente. Son un total de treinta textos que se ordenan en torno a siete bloques. El primero de los bloques recoge los textos de cuatro de los ponentes invitados. El resto de bloques recoge los textos de algunas de las treinta y dos comunicaciones que, tras un arduo proceso de selección, fueron admitidas.

\section{Ponencias invitadas}

El primero de los textos, titulado "La democracia y los derechos universales frente al auge del populismo", es autoría de Stéphane Dion, Enviado especial ante la Unión Europea y Europa y Embajador de Canadá en Alemania. El texto se corresponde con la conferencia inaugural que el Embajador Dion pronunció para abrir el Congreso, en la mañana del 10 de diciembre. Consta de dos partes claramente diferenciadas. En la primera parte, Dion realiza una reivindicación de la Declaración Universal de Derechos Humanos y los progresos que la humanidad ha experimentado en estos 70 años bajo su influjo. Encontraremos aquí un justo recuerdo al canadiense John Peters Humphrey, quien redactara el primer borrador de la Declaración, y a quien el profesor Olivier Barsalou dedicó una

\footnotetext{
${ }^{1}$ La profesora Emilia Bea ha publicado una excelente crónica del Congreso en el n ${ }^{\circ}$ XXXV del Anuario de Filosofía del Derecho (2019), de próxima aparición.
}

CEED Número 39 Publicación actas Congreso Internacional 70 Aniversario Declaración Universal de Derechos 
ponencia durante el Congreso. En la segunda parte del texto, Dion, asumiendo una posición liberal, se cuestiona cómo los derechos humanos y la democracia pueden verse afectados por la ola populista según él, tanto de extrema derecha como de extrema izquierda- que recorre Europa y el mundo entero. Frente a esos embates, propone compartir la experiencia de democracia liberal y multicultural canadiense, que ciertamente es un ejemplo de inclusión y de prioridad por la igualdad en derechos.

El segundo texto, "Los derechos humanos en el centro de la esfera internacional y nacional: nuevos paradigmas hacia la paz y la justicia”, corre a cargo de Fabián Salvioli, Relator Especial para la Promoción de la Verdad, la Justicia, las Reparaciones y las Garantías de No Repetición, de la Organización de las Naciones Unidas (2018-2021) y ex-presidente del Comité de Derechos Humanos de Naciones Unidas. El profesor Salvioli, conocedor de primera mano de las dinámicas internas de los organismos encargados de velar por los derechos humanos, ofrece una perspectiva crítica y a la vez esperanzadora. La falta de voluntad política por parte de los poderes es el gran handicap que afecta a la eficacia de los derechos. En la labor de garantizar los derechos humanos, por lo tanto, se necesitan las personas adecuadas, con el suficiente compromiso y los suficientes conocimientos, dispuestas a tomar el principio pro persona como guía de su actuación. Salvioli, además, realiza una excepcional síntesis de los grandes principios de los derechos humanos que nunca deben perderse de vista: indivisibilidad, interdependencia, universalidad, progresividad $-\mathrm{o}$ no regresividad $-\mathrm{y}$, por supuesto, universalidad.

El tercer texto es autoría de Francisco Fernández Marugán, Defensor del Pueblo en funciones. Bajo el título "Los defensores de los derechos humanos”, Fernández Marugán pone en valor las personas y las instituciones que trabajan en la salvaguarda de los derechos humanos. La institución del Defensor del Pueblo es sin duda una de ellas, dotada de una especial legitimidad por estar reconocida en la propia Constitución de 1978. Tras hacer un repaso de sus propias funciones, el Defensor del Pueblo enumera algunos de los retos que enfrentan quienes defienden los derechos en la actualidad, y sostiene que buena parte de los mismos están determinados por el modelo económico derivado de la globalización neoliberal, que acentúa el conflicto entre la titularidad universal de los derechos — particularmente de los derechos de tipo económico y social- y las lógicas de acumulación privada propias del mercado. Lástima que la reforma express del artículo 135 de la Constitución Española llevada a cabo en el 2011 — con el voto del entonces diputado Sr. Fernández Marugán— no apunte precisamente a resolver ese conflicto a favor de los derechos humanos. 
El texto del profesor Eduardo Ruiz Vieytez "Derechos humanos y diversidad cultural: ¿un binomio inestable?" cierra esta sección planteando una cuestión fundamental y recurrente en la teoría de los derechos humanos: la tensión entre universalidad y diversidad. Frente a las concepciones que, erróneamente, pretenden reivindicar la universalidad imponiendo la homogeneidad, Ruiz Vieytez reivindica una interpretación inclusiva y plural de los derechos. Dicha interpretación, sin embargo, resulta a menudo difícil de aplicar en el marco de los instrumentos jurídicos nacionales e internacionales de los que actualmente disponemos, cuya rigidez hace que con frecuencia se impongan los criterios de las culturas mayoritarias, a costa de los derechos de las minorías. Frente a ello cabe recordar la posición que tan claramente sostuvo Dworkin: si algo caracteriza a los derechos es por constituirse en triunfos de la minoría frente a la mayoría (2002:285).

\section{Violencia de género y derechos de las mujeres}

En este apartado dedicado a la violencia de género y a los derechos de las mujeres se recogen dos artículos que abordan el tema de forma específica. Sin embargo, conviene aclarar que la perspectiva de género y las cuestiones relativas a los derechos de las mujeres se encuentran incorporadas en muchos de los trabajos que componen este número monográfico. No podía ser de otra manera, a la vista de la persistencia de la violencia machista, que solo en el año 2018 acabó con la vida de 98 mujeres $^{2}$ y de los innumerables retos que quedan por abordar en materia de igualdad de género. Como quedó patente en el panel dedicado a la lucha contra la discriminación contra las mujeres del Congreso —en el que participaron como ponentes las profesoras Paz Lloria, Ma Eugenia Rodríguez Palop, Ruth Rubio y Colleen Sheppard - la igualdad de género es un asunto de primer orden dentro de la lucha por los derechos humanos. Y, como cualquier asunto de derechos humanos, no solamente debe interpelar a las personas afectadas, sino también a quienes injustamente resultan privilegiados como consecuencia de un determinado orden social. En este caso, claro está, los varones. Los emergentes estudios sobre masculinidades resultan, en este sentido, un campo por explorar en el terreno de los derechos humanos. Como ha expresado Connell, promover una profunda reforma de las masculinidades es, antes que nada, una cuestión de justicia (2005: 83, 229).

\footnotetext{
${ }^{2}$ La información completa puede encontrarse en: https://gestion.feminicidio.net/articulo/listado-feminicidios-y-otros-asesinatos-mujerescometidos-hombres-espa\%C3\%B1a-2018 [fecha de consulta: 22 de marzo 2019].
}

CEED Número 39 Publicación actas Congreso Internacional 70 Aniversario Declaración Universal de Derechos 
Encarna Canet Benavent y Gloria María Caravantes dedican un artículo a "La normativa en materia de violencia machista como garante de los derechos de las mujeres". Tras contextualizar el concepto de violencia machista, las profesoras Canet y Caravantes realizan un repaso de las principales normas internacionales y nacionales en la materia, valorando los distintos avances y retrocesos. Concluyen resaltando que la igualdad de género y el empoderamiento de mujeres y niñas es uno de los Objetivos de Desarrollo Sostenible marcados por la ONU en la Agenda 2030. Y es que, en efecto, no puede haber un progreso humano real mientras la lacra de la violencia machista continúe siendo el día a día de millones de mujeres en el mundo.

Francisco Miguel Rodríguez Rodríguez, por su parte, escribe sobre "Los derechos humanos de las víctimas de trata con finalidad de explotación sexual". Las mujeres y las niñas son las principales perjudicadas del negocio global que supone la trata de personas. El texto contextualiza el concepto de trata para, a continuación, incidir en las obligaciones que el derecho internacional impone a los estados para hacer frente a esta aberrante práctica. Como pone de relieve Rodríguez, no es suficiente proclamar los derechos en abstracto, sino que deben acompañarse de políticas públicas y actuaciones concretas por parte de los estados que garanticen la efectividad de tales derechos.

\section{Empresas multinacionales y derechos humanos}

Antes se ha dicho que los estados no dejan de ser en potencia grandes violadores de derechos humanos. Pero la realidad de la globalización, que provoca la concentración del poder —económico, financiero y, en la práctica, también político- en las manos de un número relativamente pequeño de agentes privados, hace que quienes se preocupan por los derechos humanos deban dirigir su atención también hacia las prácticas de esos agentes. Muestra de ello son tres de las comunicaciones que se presentaron en el Congreso relativas a distintos aspectos de la relación entre los derechos humanos y las empresas multinacionales.

En el artículo "Derechos humanos y empresas transnacionales: las debilidades del tercer pilar derivadas de las normas de promoción de inversiones", Adoración Guamán realiza una apuesta decidida por instrumentos internacionales vinculantes para las empresas multinacionales, en la línea de lo marcado por la histórica Resolución 26/9 del Consejo de Derechos Humanos de la ONU en 2014. Guamán rechaza la vía del soft law — encarnada fundamentalmente en los Principios Ruggie - por haberse demostrado completamente insuficiente para garantizar el acceso a la justicia de las víctimas de las

CEFD Número 39 Publicación actas Congreso Internacional 70 Aniversario Declaración Universal de Derechos 
violaciones de derechos humanos perpetradas por las multinacionales y su correspondiente reparación. Como ejemplo se toma el famoso caso Chevron contra Ecuador, donde tras el último laudo del tribunal arbitral de La Haya (agosto de 2018) se confirma que la falta de instrumentos vinculantes provoca que las violaciones — acreditadas - de derechos humanos cometidas por la multinacional petrolera queden impunes, al privilegiarse la protección de las normas bilaterales sobre inversiones por encima de las normas del derecho internacional de los derechos humanos.

Sobre esa misma tesis de la necesidad de construir instrumentos vinculantes abunda, desde el punto de vista del derecho internacional privado, Lorena Sales en su artículo "La vigencia de los Derechos Humanos en la actualidad: hacia la justiciabilidad como medio y como fin en las relaciones entre Derechos Humanos y Empresas”. Sales insiste, además, en el concepto de esclavitud moderna, y aporta datos que sin duda deben hacernos reflexionar y actuar frente al nuevo absolutismo impuesto por los poderes financieros transnacionales que, en palabras de Ferrajoli (2011b), se constituyen como "poderes salvajes". Salvajes en tanto que actúan sin vinculación alguna a la ley y, por lo tanto, absolutamente al margen de la dinámica del moderno estado derecho.

El apartado se complementa con el artículo de Estrella del Valle "Reflexiones en torno al futuro del principio de jurisdicción universal y su aplicación a la criminalidad de las empresas transnacionales". En él, la autora apunta hacia otra vía complementaria a través de la cual exigir responsabilidad a las empresas multinacionales por sus violaciones de derechos humanos: la jurisdicción universal. Concebida como el último remedio jurídico en la lucha contra la impunidad, cuando — como es el caso - el derecho internacional se muestra inoperante ante las más graves violaciones de derechos humanos, la jurisdicción universal ejercida por los estados con verdadera vocación democrática es un recurso que no cabe ser pasado por alto. Las restricciones legislativas y jurisprudenciales que el principio jurisdicción universal ha sufrido en España durante los últimos años atestiguan, precisamente, el potencial de esta vía y; al mismo tiempo, la magnitud del poder fáctico con el que nos enfrentamos.

\section{Memoria histórica y derechos humanos}

La memoria histórica es otro de los grandes asuntos en la actual agenda del movimiento por los derechos humanos. La Ley de Amnistía de 1977 y la interpretación que de ella han realizado los tribunales — disociada de la vigencia de múltiples instrumentos de derecho internacional válidamente ratificados por España — han impedido el acceso a la justicia a víctimas de crímenes de lesa humanidad 
y han asegurado la impunidad de los victimarios. Tres de las comunicaciones presentadas al Congreso dan cuenta de esta situación desde distintas perspectivas.

Yolanda Blasco, desde la historia del derecho, presenta el trabajo titulado "El exilio republicano español a la luz del movimiento por los derechos humanos en Naciones Unidas. Notas para su estudio". En él se señala la influencia que pudieron ejercer los académicos republicanos españoles en el exilio sobre la gestación de la Declaración Universal de Derechos Humanos. Un momento particularmente significativo fue la reunión que tiene lugar en La Habana en 1943, durante la cual se tomó como referencia la Carta Atlántica de 1941 para el diseño de una transición que nunca llegó a ser. Los esfuerzos, sin embargo, no cayeron en saco roto y, como Blasco muestra, llegaron a influir al menos indirectamente en la Declaración.

Raquel Vanyó, por su parte, escribe el trabajo "Niños robados: deberes pendientes para España en el acceso a la verdad, la justicia y la reparación". Como su título indica, en el trabajo se aborda la cuestión de los miles de menores que durante el franquismo - y aun con posterioridad — fueron sustraídos de sus madres en el marco de un plan sistemático que tuvo como principal objetivo la eliminación de la oposición ideológica al régimen. La gravedad de lo acontecido hace sostener a Vanyó que estamos frente a un crimen de lesa humanidad y, en particular, ante un delito de desaparición forzosa. En la medida en que este tipo penal es un delito continuado, la autora entiende que no es aplicable la prescripción y que, por lo tanto, subsiste la obligación de investigar, juzgar, sancionar y reparar por parte del estado.

Complementariamente, Irene Vázquez titula a su trabajo "La amnistía: un obstáculo al ejercicio de la jurisdicción universal sobre crímenes internacionales. El caso de España”. Vázquez profundiza en el concepto de amnistía y distingue entre diversos tipos para, a continuación, ponerlas en relación con el tratamiento que se les ha otorgado desde las distintas instancias del derecho internacional. En concreto, se destacan las observaciones que organismos como el Comité de Derechos Humanos (2009 y 2015) han realizado sobre la Ley de Amnistía española, confirmando su incompatibilidad con el 14.7 del Pacto Internacional de Derechos Civiles y Políticos, vigente en España ya con anterioridad a la aprobación de dicha ley. Se destaca, por último, la palmaria incoherencia en la que incurren los tribunales españoles, que se han parapetado tras la Ley del 77 para negarse a colaborar con la justicia argentina en la investigación derivada de la querella interpuesta por las víctimas del franquismo,

CEED Número 39 Publicación actas Congreso Internacional 70 Aniversario Declaración Universal de Derechos 
mientras que en el caso Scilingo, cuando España ejerció su jurisdicción universal, se desestimó la validez de la ley amnistía argentina precisamente por generar impunidad.

\section{Nuevos escenarios y nuevas garantías para los derechos}

Esta sección es, con diferencia, la más extensa de este monográfico y se compone de ocho trabajos. El común denominador de los ocho reside en que sus autores identifican problemas contemporáneos de derechos humanos y realizan propuestas en clave normativa para tratar de contribuir a su solución. Se trata de problemas que, en la mayoría de casos, ni tan siquiera se habían planteado hace unos años y que hoy, en cambio, se han convertido en preocupaciones centrales. Puesto que la realidad discurre habitualmente más deprisa que el derecho, este necesita evolucionar constantemente y adaptarse a nuevos escenarios. La teoría y la práctica de los derechos humanos es, por lo tanto, dinámica y requiere de constantes actualizaciones que sirvan para consolidar lo ya ganado.

María Torres escribe el texto "La protección en la jurisdicción penal internacional del derecho a la cultura: los crímenes internacionales de la destrucción del patrimonio cultural”. En él se plantea la posibilidad, reconocida por el derecho internacional, de perseguir la destrucción del patrimonio cultural como crimen de guerra y como crímenes de lesa humanidad o incluso de genocidio, siempre que vayan acompañados de un ataque sistemático contra la población con una determinada finalidad. En la línea de lo apuntado por la UNESCO, en efecto, las conductas que dañan el patrimonio cultural, dañan los derechos de la entera humanidad.

Ignacio Álvarez, por su parte, se preocupa por la protección de otro derecho de los conocidos como DESC: el derecho al agua. En el artículo "La necesaria codificación del derecho humano al agua potable y el saneamiento" volvemos a encontrar una crítica a los instrumentos de soft law y una reivindicación de instrumentos convencionales para la adecuada garantía de este derecho esencial. En un escenario mundial como el que se avizora, en el que el agua promete ser un elemento geoestratégico clave, reconocerla y garantizarla como un derecho al que puedan acceder todas las personas es ciertamente una obligación inaplazable.

En esa línea de preocuparnos por los cambios medioambientales incide el siguiente trabajo, firmado por Daniel Gracia: "Desplazados medioambientales y derechos humanos: una construcción conceptual sine qua non para su protección jurídica internacional". Como anuncia su título, el texto se preocupa 
particularmente por precisar el concepto de desplazado ambiental para, a continuación, estudiar su encaje en las distintas categorías jurídicas ofrecidas por el derecho internacional.

Siguiendo con los desplazamientos humanos, Francisco de Asís Peña escribe el texto "Credibilidad de los solicitantes de asilo y estereotipos heterosexistas: en busca del refugiado LGTBI por antonomasia". En él se trabaja la intersección entre dos situaciones que implican con frecuencia la vulnerabilidad de las personas: la condición de solicitante de asilo y la condición de minoría sexual. Las autoridades que toman una decisión que puede salvar la vida de una persona, como es la de conceder el asilo, no dejan de estar embebidas de un sistema heteropatriarcal que construye ciertos estereotipos asociados a las personas LGTBI. En esa medida, sostiene el autor, una correcta garantía del derecho de asilo requiere de mecanismos que permitan identificar y superar los estereotipos y los prejuicios. Si la cultura de los derechos humanos es la cultura del respeto por la diversidad, tales prejuicios no tienen cabida, y menos entre quienes actúan en nombre del estado.

A continuación Olga Lenzi presenta el artículo "El trabajo decente en la era digital: colectivos más vulnerables". De nuevo, la actualidad del tema es absoluta. Ante la creciente digitalización y robotización de la economía, con unas previsiones que apuntan a que una buena parte de los actuales empleos podrán ser sustituidos por procesos automatizados en los próximos años, se hace imprescindible preguntarse por los efectos que tales evoluciones tendrán sobre las personas que hoy trabajan. Y, particularmente, como hace Lenzi, sobre las personas pertenecientes a los colectivos más vulnerables. Si estos colectivos ya se ven afectados hoy por una escalofriante precariedad laboral, el siguiente paso puede ser directamente la absoluta exclusión del mercado de trabajo. Frente a ello la autora apuesta por vías que deben ser complementarias: la oferta de formación específica a todas las personas trabajadoras y el fortalecimiento de los mecanismos de negociación colectiva, cuyo poder se ha visto considerablemente disminuido en los últimos años en la mayoría de sectores.

Marina Sancho escribe sobre otro tema de innegable actualidad: "Internet, Big data y nuevas tecnologías: repercusiones y respuestas del ordenamiento jurídico". En efecto, el desarrollo exponencial que han experimentado los algoritmos de gestión de datos en manos tanto privadas como públicas implican retos sin precedentes para la protección de derechos civiles básicos, como la privacidad, el honor o el secreto en las comunicaciones. Para hacer frente a esos retos, se plantean 
garantías jurídicas que en ocasiones toman la forma de nuevos derechos, como el llamado derecho al olvido, ya reconocido en el ordenamiento español.

Otro derecho afectado por el desarrollo sin precedentes de las tecnologías digitales es el de la libre expresión. Sobre él reflexiona Jorge Correcher en su texto "Límites penales a la libertad de expresión: sobre el enaltecimiento del terrorismo en redes sociales". El autor se centra en la modificación de los delitos de enaltecimiento del terrorismo y humillación a las víctimas introducida mediante la reforma de la LO 2/2015 y, tras el análisis de algunos de los más conocidos casos en los que los nuevos tipos han sido aplicados, concluye que más que para luchar contra una supuesta actividad terrorista, la criminalización de los delitos de opinión funge como instrumento de control de la discrepancia política e ideológica, privando al debate público del las expresiones de disenso —incluso de aquellas más radicales y, si queremos, de mal gusto_- que deben encontrar su sitio en una sociedad democrática.

Cerrando este apartado encontramos el texto "El derecho a la buena administración en el marco de la protección de los derechos humanos”, firmado por María Lidón Lara. Aunque ese derecho no ha sido reconocido como tal por la Declaración Universal ni por el resto de los principales instrumentos internacionales de derechos humanos, en los últimos años ha comenzado a desarrollarse con fuerza en ciertos ámbitos. Especialmente en el marco del derecho de la Unión Europea ha encontrado un eco considerable. Sea considerado como un derecho autónomo, o bien como un derecho instrumental existe polémica entre la doctrina sobre ese punto - lo cierto es que el buen funcionamiento de la administración y, aún más, el empoderamiento de la ciudadanía frente a la administración, constituye un marco imprescindible para que los derechos humanos puedan prosperar y ser exigidos.

\section{Contextos y vulnerabilidades}

De este apartado forman parte los trabajos que se refieren contextos específicos donde tienen lugar violaciones de derechos humanos que afectan a determinada población vulnerable. Inevitablemente, el estudio de los derechos humanos no puede quedarse en reflexiones abstractas, sino que también debe acercarse a las situaciones particulares. Mirar de cerca las realidades de las que se habla. Escuchar a las personas y a las poblaciones afectadas. Ese es precisamente el nexo de unión de los cinco trabajos siguientes.

CEFD Número 39 Publicación actas Congreso Internacional 70 Aniversario Declaración Universal de Derechos 
El primero de los trabajos es autoría de Gloria María Caravantes y se titula "Barrios vulnerables: ¿derecho a la vivienda o vulnerabilidad de derechos? Una aproximación desde la exclusión residencial". En él se realiza un análisis comparado entre los barrios de El Gatillo (Guatemala) y La Coma (Valencia) siguiendo la metodología cualitativa de la audición y la búsqueda en fuentes estadísticas sobre el índice de desarrollo humano. La autora trabaja el concepto de vulnerabilidad urbana, que implica una mirada integral al derecho humano a la vivienda. Desde este enfoque, el derecho a la vivienda no puede ser entendido de una manera puramente subjetiva e individualista, sino que se configura en el contexto de la ciudad y la sociedad en la que se vive. La satisfacción de los derechos sociales es siempre compleja y contextual, e implica la interacción con las condiciones del entorno. No basta, en este caso, con habitar una vivienda, sino que importa dónde se ubica esa vivienda $\mathrm{y}$, en consecuencia, importan las condiciones de convivencia que las autoridades públicas están obligadas a promover y mantener.

A continuación Paula Morcillo y Alberto Martínez presentan el texto "La vulneración de los principios de solidaridad y no devolución por parte del estado español en el ámbito de la protección internacional". Sobre este título general, realizan una investigación cualitativa que se basa en los resultados de 15 entrevistas realizadas a informantes clave, entre los que se encuentran funcionarios, investigadores y trabajadores de organizaciones no gubernamentales. De ellas se obtiene que las personas entrevistadas consideran que el estado español viola tanto el principio de solidaridad como el de no devolución consagrado en la Convención de Ginebra. Los autores concluyen que, siendo legítimo que un estado pueda controlar los flujos migratorios, las políticas securitarias aplicadas por España en los últimos tiempos constituyen una flagrante violación del derecho internacional así como una desnaturalización del derecho de asilo. Este hecho resulta extremadamente grave porque, como Javier de Lucas ha apuntado en numerosos trabajos, el tratamiento que, como sociedad, otorgamos a los refugiados — quienes se encuentran en la situación de necesidad más extrema - es la muestra más fidedigna de nuestra propia humanidad. O, en este caso, quizá debiéramos decir, de nuestra propia deshumanización.

Seguidamente se presentan dos trabajos que están muy relacionados entre sí por el contexto que tratan y la perspectiva desde la que lo hacen. El primero de ellos es "La inclusión educativa de las personas con discapacidad y la interfaz con los derechos humanos: avances y desafíos", elaborado por Lisiê

CEED Número 39 Publicación actas Congreso Internacional 70 Aniversario Declaración Universal de Derechos 
Marlene da Silveira Melo y Lúcia de Araújo Ramos. El segundo es "Derechos Humanos en Brasil en tiempos de Escuela sin Partido", elaborado por Wisllayne Ivellyze de Oliveira y Mariana Silva. Tanto los retos de la inclusión de los menores con discapacidad como los desafíos impuestos por la oleada neo-conservadora, que amenaza con prohibir que se hable en la escuela de cualquier tema relacionado con el género o con la sexualidad, son dos grandes asuntos que hoy preocupan a las personas defensoras de derechos humanos en Brasil; pero también en el resto del mundo.

Cierra la sección con el trabajo de Berta Rodrigo "Crimen en la playa de los Molles. La construcción de la verdad a propósito de un estudio de caso sobre la violación de Derechos Humanos en Chile". La autora aborda el fundamental tema de los medios de comunicación y su papel en el esclarecimiento de la verdad, algo que resulta imprescindible cuando hablamos de violaciones de derechos humanos. Y más si se trata de violaciones masivas de derechos, como las acontecidas durante la dictadura chilena, donde tuvo lugar el caso de estudio que se trata en el texto, el de la joven profesora Marta Ugarte. En tiempos de fake news, se hace más necesario que nunca el papel de un periodismo profesional y ético, que no esté en manos de los poderes — ni públicos ni privados — porque debe servir precisamente para que la ciudadanía tenga la información con la que hacer frente a sus abusos.

\section{Perspectivas}

En esta última sección de perspectivas se recogen cinco ensayos heterogéneos entre sí, pero que comparten el hecho de aportar una reflexión sobre algún aspecto relacionado con los derechos humanos.

El primero de ellos es el trabajo de José Manuel Sánchez Patrón "La noción de dignidad en la Declaración Universal de los Derechos Humanos”. Las cinco ocasiones en las que la Declaración hace mención al concepto de dignidad llevan al autor a realizar un recorrido por el mismo, tratando de concretar las implicaciones que tiene el uso de un concepto cuyo significado está lejos de ser unívoco. En un esclarecedor ejercicio, Sánchez Patrón repara en el fundamento, los límites y el contenido que puede asociarse con la idea de dignidad.

El siguiente trabajo corre a cargo de Joan Alfred Martínez y se titula "El neoliberalismo y su execración populista frente a los humanismos democráticos y el reto de una cultura política federalista". En él se constatan algunos elementos definitorios del sistema político y económico neoliberal, que ponen en crisis los valores e instituciones sobre los que se asienta el estado social y

CEFD Número 39 Publicación actas Congreso Internacional 70 Aniversario Declaración Universal de Derechos 
democrático que — al menos inicialmente - impulsó la Unión Europea. Las transformaciones del mundo del trabajo, los mecanismos de desigualdad y exclusión, la sublimación de las tecnologías y la atracción de las singularidades identitarias, a juicio del autor, son algunas de las manifestaciones de tal crisis. Otra manifestación, probablemente la más nueva y la más peligrosa — porque refuerza a todas las demás_-, es el auge de los populismos. Frente a ellos, sostiene el texto, es necesario oponer la tradición de los humanismos democráticos y la cultura política federalista, que ciertamente se encuentran en la base del desarrollo del derecho internacional, incluido el derecho internacional de los derechos humanos.

A continuación encontramos "El sistema de hard-law y de soft-law en relación con la defensa de los derechos fundamentales, la igualdad y la no discriminación”, autoría de Luis Francisco Sánchez. El texto realiza una amplia revisión de los aspectos positivos y negativos de ambas técnicas regulatorias. A diferencia de otros de los trabajos presentados en este monográfico, se apunta la existencia de un espacio propio para las normas de soft-law que, bajo ciertas circunstancias, pueden facilitar la obtención de acuerdos entre actores internacionales con muy distintos intereses y planteamientos. Sin embargo, por otra parte, no se nos puede escapar que un uso masivo de estas técnicas puede conllevar el vaciamiento de los poderes públicos en beneficio de de los grandes actores privados.

Ana Colomer escribe el texto "Hospitalidad en tiempos de exclusión: el compromiso de Dorothy Day con los derechos de los más vulnerables”. Siguiendo los pasos de Maritain o Mounier, Dorothy Day se adscribió a la línea de pensamiento personalista y, desde ella, dedicó su obra a defender la idea de hospitalidad. La autora propone recordar el compromiso cívico que caracterizó a la periodista estadounidense, y lo pone como modelo del modelo de ciudadanía que hoy, 70 años después de la aprobación de la Declaración Universal, todavía se necesita para que los derechos de todas las personas dejen de ser una mera aspiración para convertirse en realidad.

Por último, el número se cierra con el trabajo de Gerardo Mata titulado "Derechos humanos y colonialidad: 70 años de la Declaración Universal”. Ubicando sus reflexiones en un posicionamiento descolonial, Mata sostiene una enmienda a la totalidad que debería ser escuchada y tenida en cuenta por quienes nos dedicamos a los derechos humanos situados en el occidente, o en el norte geográfico. El texto aborda los condicionantes epistémicos y ontológicos que subyacen al concepto y al sujeto de los derechos humanos. Otorgar al hecho colonial la centralidad que probablemente merece dentro de la 
historia de la modernidad, como hace el autor, cambia el paradigma y subvierte los órdenes con los que estamos habituados a manejarnos en la filosofía y el derecho occidental. Al hacerlo, la pretensión de universalidad se ve enfrentada a su objeción más seria, y tiene el deber de proporcionar una respuesta igualmente seria y convincente a quienes se sienten presos de una historia y un relato que no son los suyos.

\section{Conclusión}

Este número especial de Cuadernos Electrónicos de Filosofía del Derecho, en definitiva, recoge una colección plural de reflexiones sobre los derechos humanos. Constituye, me parece, una buena muestra del interés que siguen despertando hoy los derechos humanos en distintas áreas del conocimiento. Mantener viva y activa una cultura de los derechos es un elemento fundamental para su protección. De la misma manera, fomentar la discusión y el intercambio de ideas entre quienes se dedican a los derechos humanos desde la academia contribuye a aumentar la calidad de los análisis y de los argumentos. Ese fue uno de los objetivos del Congreso Internacional del 70 Aniversario de la DUDH que organizamos en Valencia y que ha dado lugar a esta publicación. Retomando de nuevo la idea de Jhering, de lo que se trata no es de forjar una academia complaciente cuya agenda venga marcada por los intereses de los poderes de turno. De lo que se trata cuando trabajamos por y para los derechos humanos, es de ejercer una teoría y una praxis crítica, formando personas que sean capaces de decir la verdad al poder.

CEFD Número 39 Publicación actas Congreso Internacional 70 Aniversario Declaración Universal de Derechos 
Bibliografía

CEAR (2018), Informe 2018: Las personas refugiadas en España y Europa, disponible online en https://www.cear.es/wp-content/uploads/2018/06/Informe-CEAR-2018.pdf, [fecha de consulta: 22 de marzo 2019]

Connell, R. W. (2005), Masculinities (2 ${ }^{\mathrm{a}}$ ed.), Cambridge, Polity

Dworkin, Ronald (2002 [1977]), Los derechos en serio, trad. de Marta Gustavino, Madrid, Ariel

Ferrajoli, Luigi (2011a [2007]), Principia iuris. Teoría del derecho y de la democracia, 2 vols., trad. de Perfecto Andrés Ibáñez et al, Madrid, Trotta

- (2011b), Poderes salvajes. La crisis de la democracia constitucional, trad. de Perfecto Andrés Ibáñez, Madrid, Trotta

Hunt, Lynn (2007), Inventing Human Rights: A History, Nueva York, WW Norton

IOM (2019), Missing Migrants Project, disponible online actualizado en tiempo real: https://missingmigrants.iom.int/ [fecha de consulta: 22 de marzo 2019]

von Jhering, Rudolf (2008 [1872]), La lucha por el derecho, trad. de Adolfo Posada, Granada, Comares

Kelsen, Hans (1950), The Law of the United Nations. A Critical Analysis of Its Fundamental Problems, Nueva Jersey, Lawbook Exchange

Oxfam (2019), ¿Beneficio público o beneficio privado?, Informe de enero de 2019. Disponible online en https://www.oxfam.org/es/informes/bienestar-publico-o-beneficio-privado [fecha de consulta: 22 de marzo 2019]

Sands, Philippe (2013), “Introduction”, en Lauterpacht, Hersch (2013 [1945]), An International Bill of the Rights of Man, Oxford University Press

CEFD Número 39 Publicación actas Congreso Internacional 70 Aniversario Declaración Universal de Derechos 